\title{
Snap-through behavior and button design
}

\author{
Thomas Jin-Chee Liu ${ }^{*}$, Nai-Pin Lin \\ Department of Mechanical Engineering, Ming Chi University of Technology, Taishan, New Taipei City, Taiwan \\ *Corresponding Author: jinchee@mail.mcut.edu.tw
}

\begin{abstract}
Using the non-linear finite element analysis, the snap-through behavior of the button is studied. For the specified case, the finite element results agree with those of the experiments. From the numerical results, the forcedisplacement curves and click ratios of various button design cases are obtained. This research will provide the information of the button design for industrial engineers.
\end{abstract}

Keywords: snap-through, finite element, button design.

\section{Introduction}

As shown in Fig. 1, the snap-through problem is a typical topic in solid mechanics. Many past researches ${ }^{(1-5)}$ have studied this problem. The snap-through behavior has been applied to the button design (Fig. 2) in electronic products such like mobile phones or cameras. For example, the metal arch is adopted as an important component in the button. Under the snap-through phenomenon as shown in Fig. 1, people can feel a click or jump motion when their fingers press the button.

Figure 1 illustrates the snap-through phenomenon of an arch structure. When the applied force $F$ approaches the critical point $a$, the structure will jump and snap along the $a-c$ path. This jump motion is illustrated in Fig. 1. If the displacement-control method is adopted, the $F$-v relation will follow the $a-b-c$ path.

In this paper, the snap-through deformation of the arch shell is studied. Using the non-linear finite element analysis, the large displacement, contact condition and elasto-plastic stress-strain curves are considered. The geometry properties will be discussed for obtaining the design guidelines. Finally, this research will provide the information of the button design for engineers.

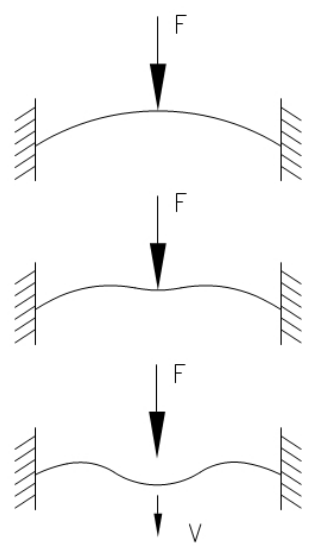

(a)

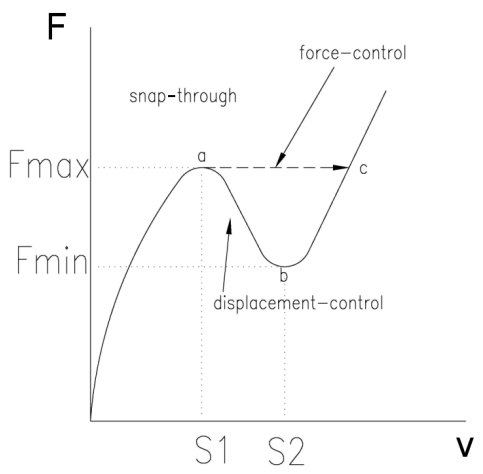

(b)

Fig. 1. (a) Snap-through deformation. (b) Forcedisplacement $(\mathrm{F}-\mathrm{v})$ relation of snap-through deformation.
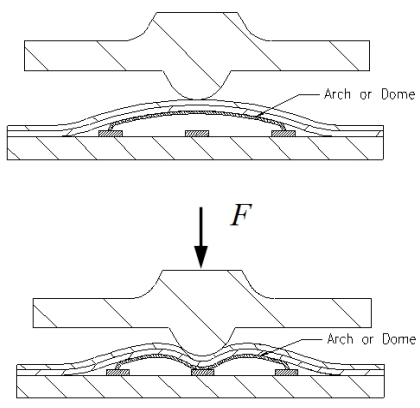

Fig. 2. Button structure. 


\section{Problem Definitions}

The configuration of this study is shown in Fig. 3. The arch shell structure has thin thickness $t$. Its main dimensions are $R, H, W$, and $t$. The indenter with radius $r$ presses the arch shell to obtain the snap-through deformation. Both ends of the arch are fixed.

Due to the relative rigidity, the indenter is assumed as a rigid body. The arch is made of metal such as aluminum or steel.
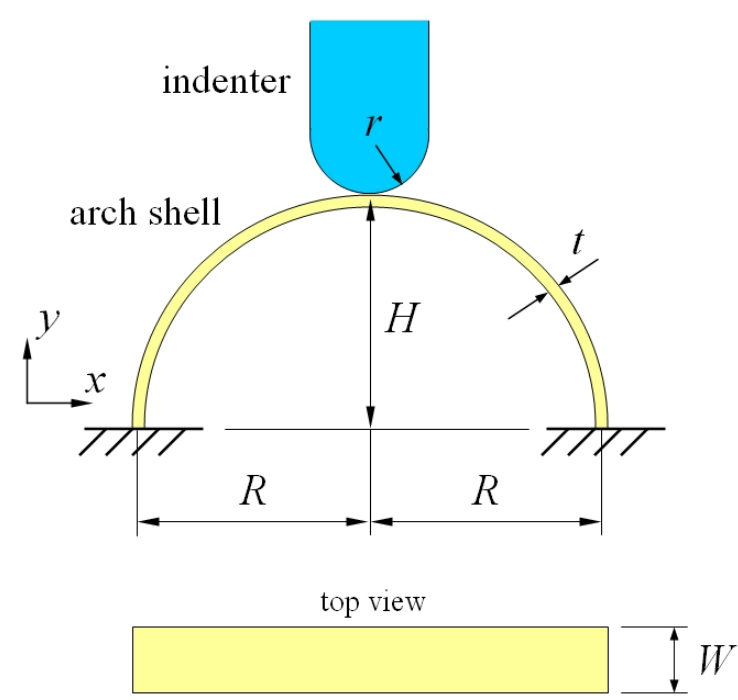

Fig. 3. The configuration of arch shells tested in this study.

\section{Methods of Analyses}

\subsection{Non-Linear Finite Element Modeling}

The large displacement, contact condition and elastoplastic stress-strain curve are considered in this paper. Above items are all non-linear. The finite element software ANSYS ${ }^{(6)}$ is adopted to solve the problem. A typical finite element mesh is shown in Fig. 4. Due to thin thickness, the arch is modeled by the shell elements, i.e. SHELL93 elements (as shown in Fig 5) ${ }^{(6)}$. The geometry dimensions of the mesh are $R=H=32.65 \mathrm{~mm}, W=15 \mathrm{~mm}, t=0.11 \mathrm{~mm}$, and $r=5 \mathrm{~mm}$. The mesh contains 4081 elements and 5943 nodes.

In ANSYS, contact conditions are given on the contact surfaces between the indenter and arch shell. TARGE170 and CONTA174 elements are used to simulate the contact surface and non-penetration condition. Due to the relative rigidity, the indenter is modeled as a rigid contact body. The contact parameters in ANSYS are $\mathrm{FKN}=0.4$ and
FTOLN $=0.05$. The shell thickness effect for the contact analysis is considered in the numerical calculation. The elasto-plastic analysis is considered because of the plastic deformation. In this case, the elasto-plastic stress-strain curve is inputted into ANSYS.

The indenter is prescribed with a displacement along the $y$-direction. This prescribed displacement can be downward and upward to control the motion of the indenter.

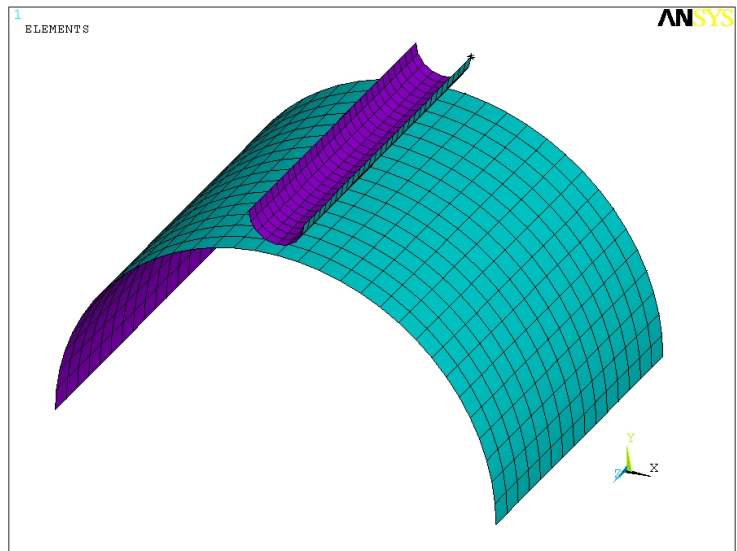

Fig. 4. Finite element mesh.

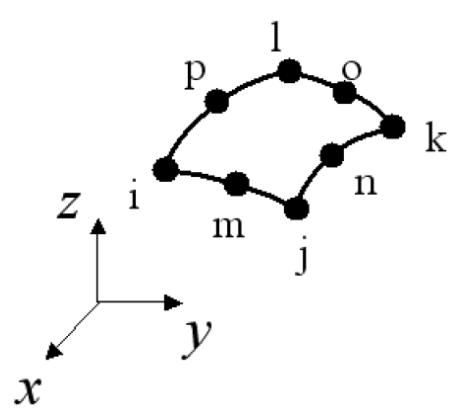

Fig. 5. SHELL93 element of ANSYS (8-node structural thick shell element).

\subsection{Experiments}

The experiments are established to ensure the validation of the finite element analysis. Experimental and finite element results will be compared.

The MTS testing system (MTS Systems Corporation, USA) shown in Fig. 6 is used in this study. Fig. 7 shows the sample and equipment. The indentation experiment such as the case in Fig. 3 will be done by the MTS system.

Also, the elasto-plastic stress-strain curve can be obtained by the tensile test in the MTS system. Fig. 8 and 9 respectively show the testing results of the aluminum alloy (Al-Mn 3004) and stainless steel plate (JIS SUS 301 EH). It 
represents the engineering stress and strain. It must be converted to the true stress-strain data for the finite element analysis. In addition, Table 1 lists the material constants obtained by the tensile test.

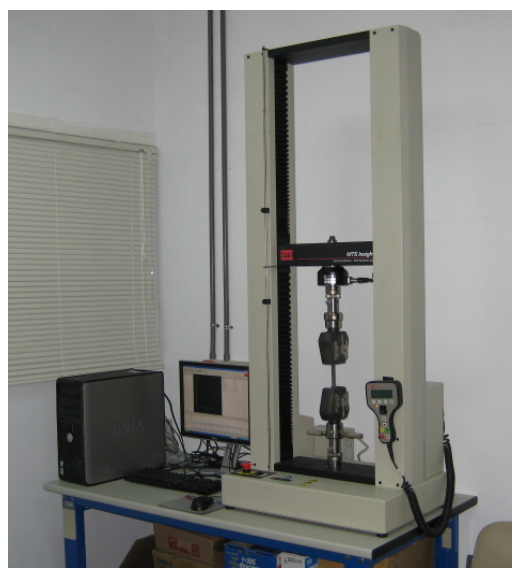

Fig. 6. MTS testing system (MTS Systems Corporation, USA).

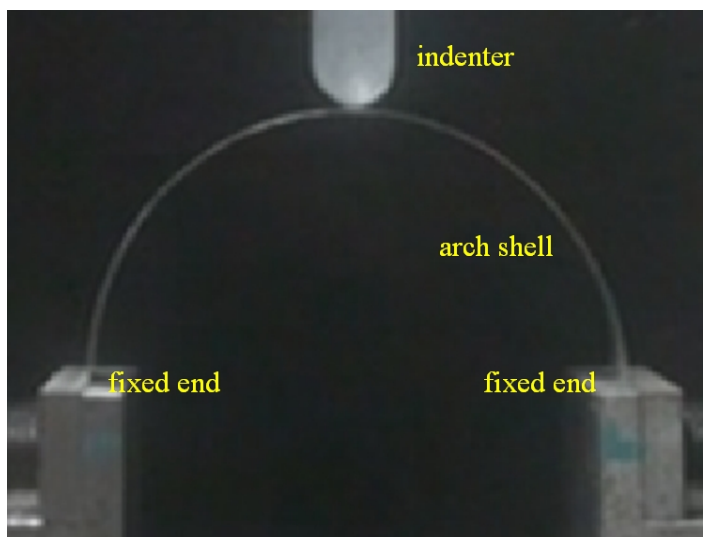

Fig. 7. Indentation experiment.

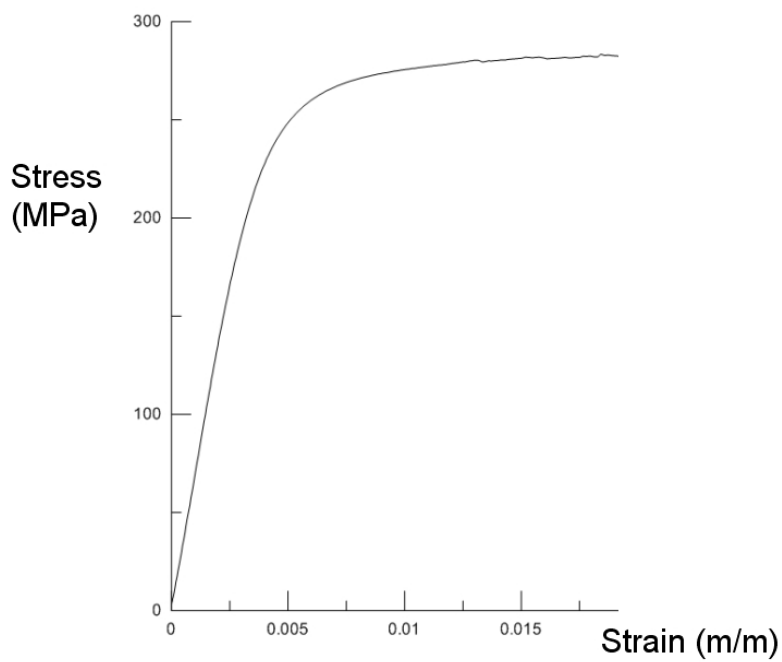

Fig. 8. Elasto-plastic stress-strain curve of aluminum alloy (Al-Mn 3004).

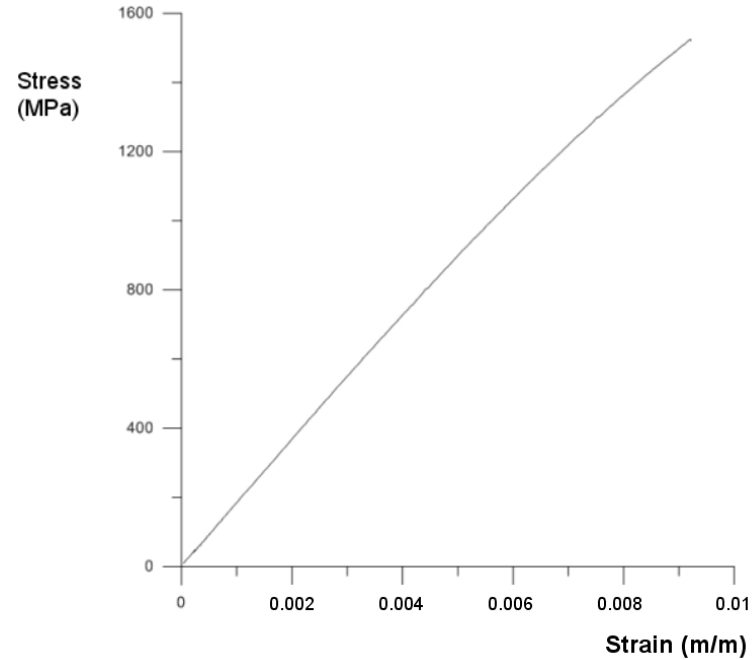

Fig. 9. Elasto-plastic stress-strain curve of stainless steel (JIS SUS $301 \mathrm{EH}$ ).

Table 1. Material constants.

\begin{tabular}{|c|c|c|c|}
\hline \hline Material & $\begin{array}{c}\text { Young's } \\
\text { modulus } E \\
(\mathrm{GPa})\end{array}$ & $\begin{array}{c}\text { Poisson's ratio } \\
v\end{array}$ & $\begin{array}{c}\text { Yielding strength } \\
(\mathrm{MPa})\end{array}$ \\
\hline $\begin{array}{c}\text { Aluminum alloy } \\
\text { (Al-Mn 3004) }\end{array}$ & 68.82 & 0.34 & 257.77 \\
\hline $\begin{array}{c}\text { Stainless steel } \\
\text { (SUS 301 EH) }\end{array}$ & 186 & 0.3 & 1250 \\
\hline \hline
\end{tabular}

\subsection{Design of Button}

The click ratio $C R$ is an important parameter for the button and switch design. Referring to Fig. 2, the definition of $C R$ is as follows:

$$
C R=\left(F_{\max }-F_{\min }\right) / F_{\max } * 100 \%
$$

where $F_{\max }$ and $F_{\min }$ denote respectively the maximum and minimum force during the snap-through deformation. Larger $C R$ value represents more obvious jump motion when people's finger presses the button or switch. Referring to the past study ${ }^{(7)}$, the click ratios are designed within the range $30 \%$ to $60 \%$ to obtain good feeling for people's fingers.

\section{Results and Discussions}

\subsection{Validation of Finite Element Modeling}

In this section, experimental and finite element results are compared to confirm the modeling accuracy. The 
material of the arch shell is Al-Mn 3004 aluminum alloy. The following dimensions are considered: $R=H=32.65 \mathrm{~mm}$, $W=15 \mathrm{~mm}, t=0.11 \mathrm{~mm}$, and $r=5 \mathrm{~mm}$. Fig. 10 and 11 show the snap-through results from the testing and ANSYS. It shows good agreement between both data. The accuracy of the finite element modeling is valid.

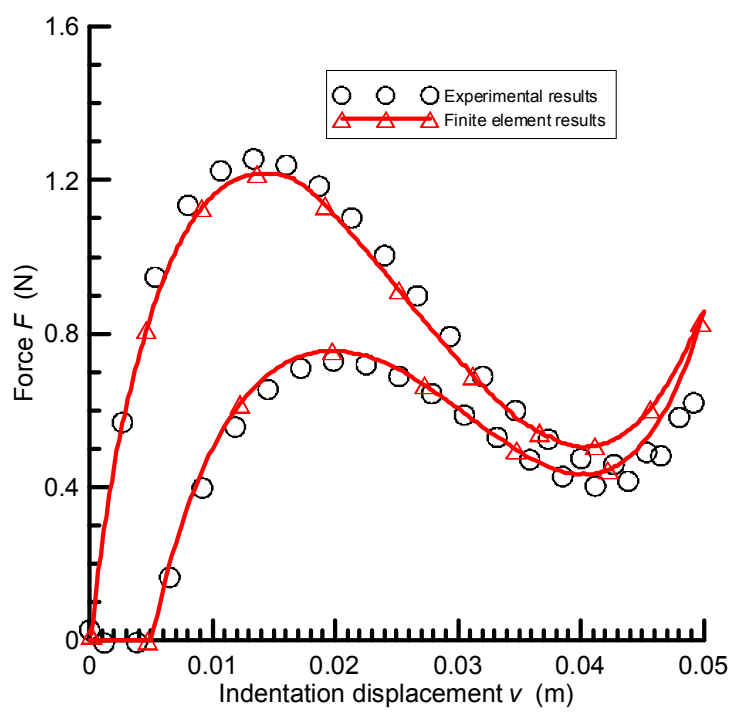

Fig. 10. Snap-through results obtained from experiments and ANSYS. (Applied force versus indenter's displacement)
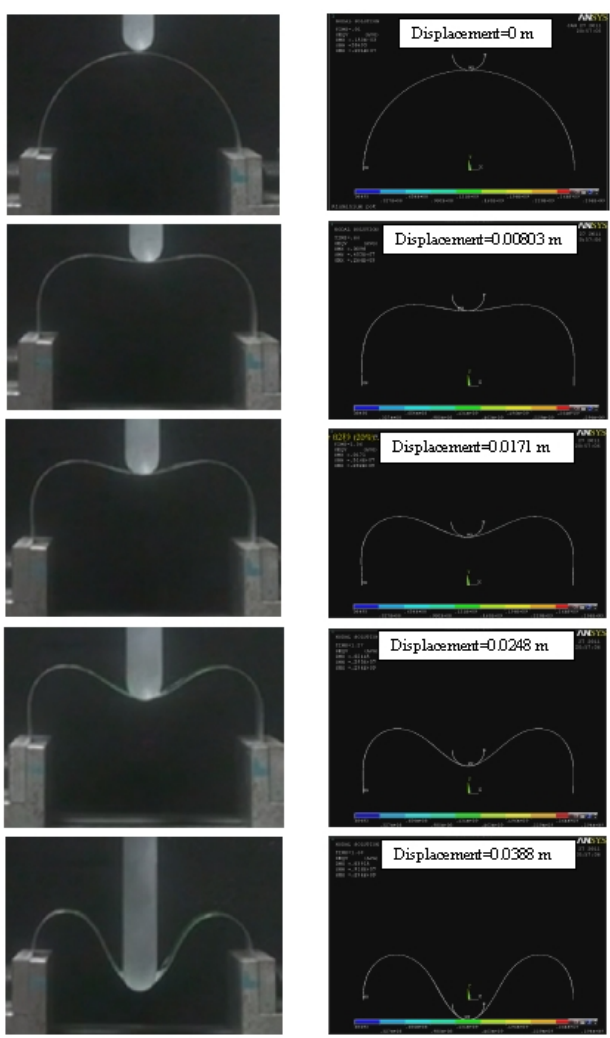

$\mathrm{b}$

Fig. 11. Snap-through results obtained from experiments (Fig. a) and ANSYS (Fig. b).

\subsection{Design and Analysis for Button}

In this section, the arch shell's size is reduced to fit the design size for the button in electronic products. The following dimensions are used: $H=R=2 \mathrm{~mm}, W=3 \mathrm{~mm}$, $t=0.06 \mathrm{~mm}$, and $r=0.25 \mathrm{~mm}$. The material is the stainless steel (JIS SUS $301 \mathrm{EH}$ ). The arch is subjected to cyclic loadings of the indenter. Fig. 12 shows the relation between applied force and indenter's displacement. The results of the first loading cycle show that the arch shell has large plastic and permanent deformation. In the second and third cycle, the arch loses the snap-through behaviors so that this structure cannot be the component of the button.

To fit the design functions, the new dimension $H=0.1 R$ is adopted. Fig. 13 shows the results from three different shell thicknesses $(t=0.05,0.06$, and $0.07 \mathrm{~mm})$. The indenter is loaded and then unloaded to its original location. In the first cycle, the loading and unloading paths are different due to the plastic deformation. In the second and third cycle, the operation paths follow the unloading path of the first cycle. The snap-through behavior exists for the button design.

The values of the click ratios are obtained from the second cycle and listed in Table 2. Referring to the past study ${ }^{(7)}$, the click ratios are designed within the range $30 \%$ to $60 \%$ to obtain good feeling for people's fingers. The cases of $t=0.05 \mathrm{~mm}$ and $0.06 \mathrm{~mm}$ fit the criterion.

In addition, Fig. 13 shows that the applied force becomes larger when the thickness is larger.

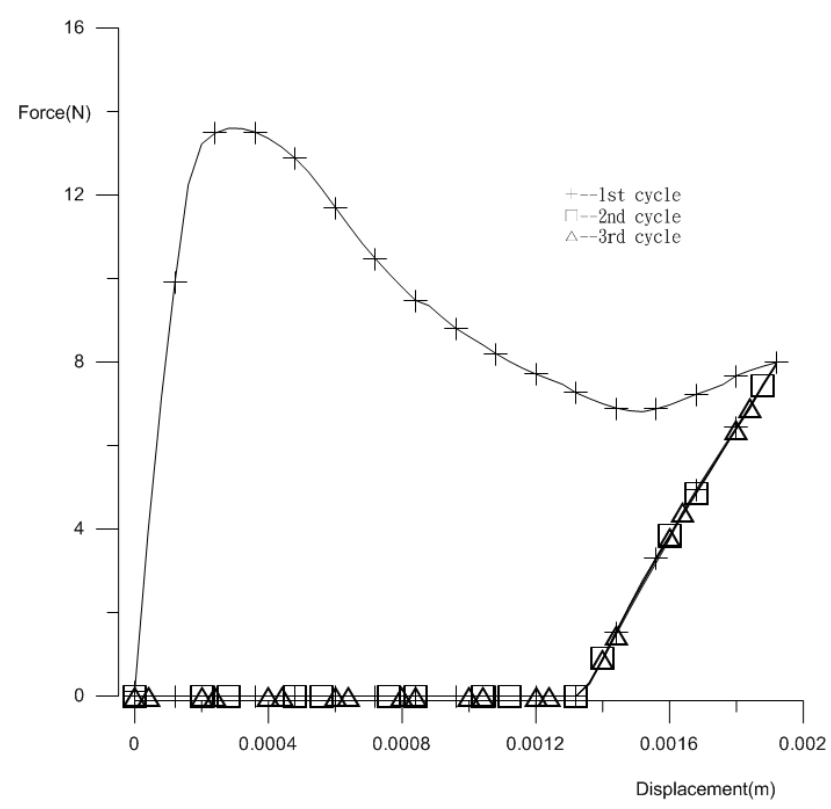

Figure 12. Relations between applied force and indenter's displacement. $(H=R=2 \mathrm{~mm})$ 


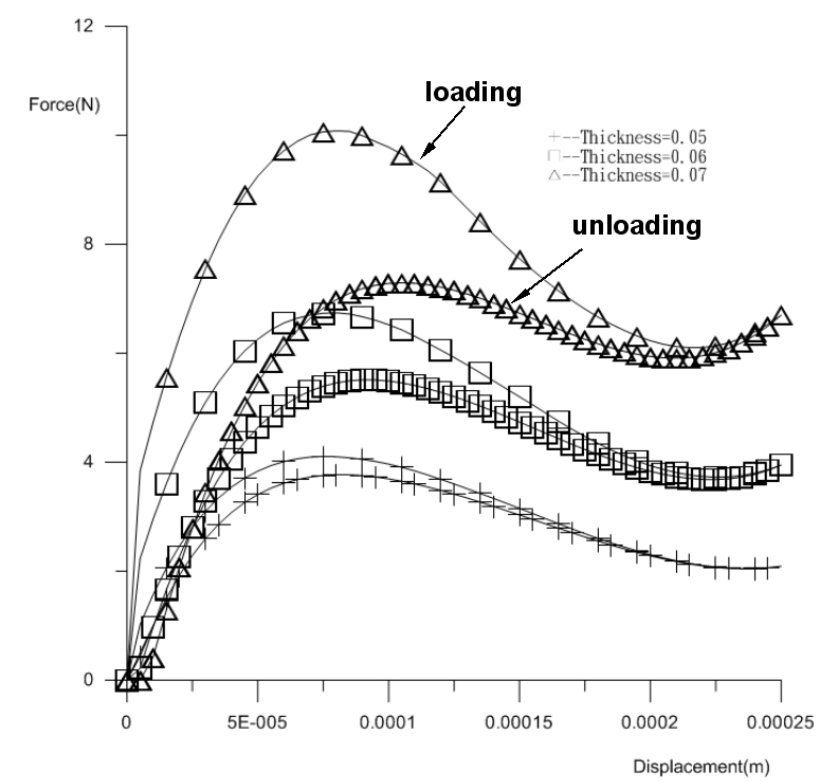

Figure 13. Relations between applied force and indenter's displacement. $(R=2 \mathrm{~mm}, H=0.1 R)$

Table 2. Click ratios from second loading cycle.

\begin{tabular}{|c|c|c|c|}
\hline \hline $\begin{array}{c}\text { Thickness } \\
(\mathrm{mm})\end{array}$ & $C R \quad(\%)$ & $F_{\max }(\mathrm{N})$ & $F_{\min }(\mathrm{N})$ \\
\hline 0.05 & 45.77 & 3.7709 & 2.0448 \\
\hline 0.06 & 33.17 & 5.5123 & 3.6837 \\
\hline 0.07 & 18.98 & 7.2942 & 5.9100 \\
\hline \hline
\end{tabular}

\section{Conclusions}

In this paper, the snap-through behavior of the arch shell have been studied and discussed. The shape of the arch shell affects the snap-through behavior. The case of $H=R$ loses the snap-through behaviors. With $H=0.1 R$, it presents the snap-through behavior for the button design. The click ratios are designed within the range $30 \%$ to $60 \%$ to obtain good feeling for people's fingers.

\section{References}

(1) D.O. Brush and B.O. Almroth: Buckling of Bars, Plates, and Shells. McGraw-Hill, New York, 1975.

(2) G. Wempner and D. Talaslidis: Mechanics of Solids and Shells: Theories and Approximations. CRC Press, New York, 2003.

(3) J.V. Huddleston: "Finite deflections and snap-through of high circular arches", ASME J. Appl. Mech., Vol. 35, pp. 763-769, 1968.

(4) J.F. Mescall: "Large deflection of spherical shells under concentrated loads", ASME J. Appl. Mech., Vol. 32, pp. 936-938, 1965.

(5) K.J. Bathe and H. Ozdemir: "Elastic-plastic large deformation static and dynamic analysis", Comput. Struct., Vol. 6, pp. 81-92, 1976.

(6) ANSYS Inc.: ANSYS HTML Online Documentation. SAS IP, Inc., USA, 2005.

(7) T. Tomitsuka, S. Ajimura, T. Kawahira and Y. Noguchi: Fujikura Technical Review 104 (2003) 42-46. (in Japanese) 